\title{
The Amount of Water and Flour Particles Size Role in Gluten-Free Bread Production and Quality Evaluation
}

\author{
Vikendra Dabash \\ Department of Food Technology, Faculty of Technology, Tomas Bata University, \\ Zlín, Czech Republic \\ E-mail: dabash@utb.cz, vikendradabash@rediffmail.com
}

Iva Buresova

Department of Food Technology, Faculty of Technology, Tomas Bata University, Zlín, Czech Republic

Richardos Nikolaos Salek

Department of Food Technology, Faculty of Technology, Tomas Bata University, Zlín, Czech Republic

Received: November 7, 2018 Accepted: December 8, 2018 Published: December 11, 2018

doi:10.5296/jfs.v8i1.14040

URL: https://doi.org/10.5296/jfs.v8i1.14040

\begin{abstract}
Gluten-free products' market is increasing day by day. Keeping to improved indicative methods, many people are recognized who are suffering with coeliac disease. Presently, the gluten-free foodstuffs which is safe for consumable for coeliac disease people, the market is growing rapidly. By using different types of cereals and flours makes it important to discover the other possibilities to take over the chore of gluten by other flour or flour components, by the increase of different components by substituting the various flours and baking process alteration. By the drive of this review, the author is to explain a summary of the water volume which used in the manufacturing of gluten-free bread and quality, to raise the manufacturing quality of gluten-free bread have already recorded procedure and ingredients in a single use assistance. The aim and goal of this review article is importance of water in gluten free bread baking.
\end{abstract}




\section{Macrothink}

Keywords: Gluten-free bread, Rice flour, Emulsifiers, Dough, Flour particle, Rheological properties

\section{Introduction}

At present time baking the gluten-free bread is a big mission for the bakers and cereal scientists. The other components are the substitutes for gluten-free bread baking which transfer the job of gluten to form a three-dimensional protein network throughout dough preparation. at the present time, the market for the gluten-free foodstuffs has been growing due to the increasing the number of celiac diseases people. (Gallagher et al., 2004). Due to the increase in the celiac disease, the rapidity is founded (Mendoza, 2005). Scientists and bread manufacturers noticed a great effect on the dough rheology, methods, and the absence of gluten in the dough caused of the GF food stuffs quality (Cauvain, 1998). The gluten-free doughs have less cohesive and elastic in comparison of wheat dough. The GF doughs are less flexible, extremely smooth, hard to handling, the better of cake is need extra handling (Schober et al., 2005). It works, the betters word uses on the place of these GF doughs often. The doughs mixed in a mixing macines frequently, because, manually mixing consumes a lot of energy (Moore et al., 2004). French bread texture is crumbled and their crumbs are color is lighter, these qualities deficits show in the final finishing products (Gallagher \& Gormley, 2002), and the volume of the final food products are frequently slighter, due to, during raising their tiny carbon dioxide binding activity (Rosell, 2009). According to the principal to a firmer crumb and softer crusts, Gallagher et al. (2003) the water molecules diffuse earlier into the crust because they are not firmly bounded in the crumb, it is based on the absent connections. There are some weaknesses in gluten-free bread (Gallagher et al., 2003), like as particles finding in the mouth through ingesting, a short shelf life, a dry mouth sense and not really acceptable. GF flours, starches, and hydrocolloids used for the Outmoded bakery foodstuffs' for discover are possible by the new technology development (Arendt, 2002). To reaching the best significant facts for being effective are varying the capacity of the gas-binding and the steadiness of gel starch at the time of baking (Cauvain, 1998). Dissimilar recipes for substituting the gluten network and its functionality used due to the normal, artificial and biotechnological hydrocolloids, these belong to their great water binding capacity and their structure creating a performance frequently (Rosell, 2009). The volume of bread obtained from fine flour was affected by the water amount. At the time of making gluten-free bread, the plasticizer result of the water is crucial, because during mixing it contributes to the extensional properties (Macro \& Rosell, 2008). Attained by bread obtained from fine flour and low water content $(70 \%)$ could be the clarification of the very low specific volume. Nevertheless, the hydration of the particles is due to the increase in water amount. Then the shortage was partially corrected. (Han et al., 2012) reported, overdevelopment during baking resultant in large volume bread due to the unnecessary water. Nevertheless, in coarse flour containing indicating the more visible effect and big holes in the crumb bread due to much water led. The two-way ANOVA interaction graph was used for the observation for the mutual effect of flour particle size and recipe water content (De la Hera \& Gomez, 2013). By increasing the water content, the variances in bread specific volume derived from diverse particle size can be minimized with the optimal water content for this particle size is around $90-110 \%$, the significant variances did not show by the specific volume 


\section{MInstitute ${ }^{\text {Macrothink }}$}

of bread made with coarse flour and $90 \%$ or $110 \%$ of water. Significantly higher weight loss indicated by the coarse flour led to bread with lower bread with lower water holding ability, by higher water content it was improved as well accredited to the lower hydration ability of the coarse particles compared to the fine ones due to the lower water retention. In fact, (Rosell, 2013a) reported, this was clarified by the lower surface area of large particles in comparison with the small ones by the alike particular behavior. A great effect on the bread quality is due to the Gluten-free breads are mainly starchy matrixes where the complete gelatinization of the starch. if enough water is present then the Starch gelatinization be ensured, because of that batters resembled very often by the gluten-free doughs. Significantly contribute to dough consistency due to the gelatinized starch is present at the initial stages of bread making. In fact, for increasing dough consistency, adhesiveness, springiness, and stickiness, (Brites et al., 2010) applied flour blanching for made corn gluten-free bread. The rest of water and ingredients were mixed, proofed and baked when Blanching consisted in adding boiling water (77\%) to corn flour and after mixing it was left idle till cooling. Responsible for the dough textural properties was the flour blanching gelatinized part of the corn starch. Developing rice-based bread the same stratagem was applied by (Macro \&d Rosell, 2008).

\section{Materials and Methods}

For manufacturing GF bread as the raw materials, the profitable thick mixture of gluten-free flour as a control sample and three types flours were used. Gluten-free bread dough had these nutritional facts by $0.7 \%$ protein, $83.3 \%$ carbohydrate, and $0.2 \%$ fat. ISO 11085:2006 (Kjeldahl method), was used for the protein evaluation, ISO 2171:2007 was used for ash estimation, by a variance among the protein, fat, and ash contents in flour evaluated the fat content (Wronkowska \& Soral-Smietana, 2008). CF- 100/100g; RF-100/100g; CRF-50:50/100g, buckwheat, BRCF- 30:35/100g, and the profitable gluten-free bread tick mixture as a control, these were the five designs which were used in this research. From the formerly research the 30/100g buckwheat addition level was selected (Sakac et al., 2011). According to formerly defined, bread an area derived from the vital part of the crumb pores were measured (Rozylo et al., 2015b). First and three days after baking the textural properties of the breadcrumb were tested. A ZWICK Z020/TN2S strength tester was used for the measurements slices of the loves were cut mechanically. Every sample tested in 12 replicates and the middle part of the loaf was sliced and used for tests. In this study, for the sample pressed a capital equipped with a $30 \mathrm{~mm}$ plug until a $50 / 100 \mathrm{~mm}$ depth at a cross-head speed of $1 \mathrm{~mm} / \mathrm{s}^{-1}$ was used (Rozylo, 2014a, b). The textural parameters: hardness, elasticity, cohesiveness (area2/area1), and chewiness (hardness $\times$ elasticity $\times$ cohesiveness), obtained by the when the sample for texture profile analysis it was compressed twice (Gambaro et al., 2006). The percentage changes in hardness were calculated due to storage (BS- degree of staling bread) to measure the changes (BS- degree of staling bread). Mechanically sliced samples were used, for sensory evaluation. Coded and served in the randomized directive the bread slices samples ( $1 \mathrm{~cm}$ thick), divided into 4 section and presented on plastic dishes (Matos \& Rosell, 2012). The habitual consumers and bread overall acceptability were evaluated by the panelists of the sensory evaluation, the panel had 52 untrained consumers 


\section{MInstitute ${ }^{\text {Mink }}$}

both female and male from 21 to 50 -year-old.

\subsection{Dough Properties}

Dough steadiness (water addition). In bread making the dough steadiness is a vital parameter. Usually, the final quality of bread ideal consistency for the rheological testing considered 500 $\mathrm{BU}$ of doughs, with the respect to wheat bread dough. really as a function, of the GF recipe accepted due to the numerous consistency levels, can be found in the to bear an acceptable gluten-free dough the consistency levels can be found in the research studies, such specific and robust signs are not yet available with the respect to GF bread. Into the method, in particular when ingredients having a high water empathy are comprised, to assure good dough recitals throughout leavening a lower consistency (i.e., higher water levels in the dough) has been founded as preferable with the similar gluten-free recipe used (Cappa et al., 2013). This is described in a current review that a softer crumb corresponds by the dough consistency and a low dough consistency is strongly related to the texture parameters of GF crumb (Matos \& Rosell, 2015).

\subsection{Bread Making Process}

The process of bread manufacturing was described. Accepting in the present recipe, due to use some different raw materials were some changes accepted in the bread manufacturing method which was done as described (Mariotti et al., 2016). At $5 \mathrm{~min}$ at $60 \mathrm{rpm}, 250 \mathrm{C}$ all of the powders were first-mixed with the help of robot mixer (CZ). The residual water and the edible oil (virgin olive) were used afterward the formerly added the ingredients isolated in water (maltose, $\mathrm{NaCl}$ and - when present- CY) (Rosell, 2015). The kneading of the dough was sustained up to $15 \mathrm{~min}$ after adding the all ingredients in the first 2 minutes of mixing.

Use of the leavening agent (SD-Doughs, $3 \mathrm{~h}$; CY, $1 \mathrm{~h} 30 \mathrm{~min}$; SDCY, $1 \mathrm{~h}$ ) shows the dissimilar proofing times which is $250 \mathrm{C}$ and $80 \%$ (Haereus Votsch, mod. HC0020; Frommern, Germany) of relative humidity, after that the dough was alienated into 8 aliquots, $150 \mathrm{~g}$ each, leavened in a climatic compartment after sited into baking molds (Raineri, A., 2011). The rheofermentographic test was used for the defined the ideal fermentation time of each dough. The baking time and temperature for the leavened dough were for $30 \mathrm{~min}$ at $230{ }^{\circ} \mathrm{C}$ in the baking oven (Lotous, Treviso, Italy), and after that cooled at room temperature and at last removed from the molds.

\section{Results and Discussion}

Dough competence (the amount of water addition) and the recipe composition are the main factors on which the overall appearance of GF bread is depended.it is displayed by the outcomes of the analysis. The effects on the physical features of gluten-free bread of the water amount offered by this figure. usually, when too much water was added the bread was bent. By the viable flour a large transformation in the water amount (80-110\%). mix (CC) (starch with several additives) conflicting to the rice flour which riveted very little water (80, - 90\%). almost non-porous bread was produced however the $80 \%$ water shared in dough yield but corn flour accepted only $120 \%$ unsatisfactorily. 
Table 1. One-way ANOVA was used for the textural parameters of breadcrumb

\begin{tabular}{llllll}
\hline Type of flour & Water amount $(\mathrm{g})$ & Resilience & \multicolumn{4}{l}{ Cohesiveness } & Hardness $(\mathrm{N})$ & Springiness \\
\hline Fine & 70 & - & - & - & - \\
& 90 & $0.21 \pm 0.02 \mathrm{c}$ & $0.46 \pm 0.01 \mathrm{~cd}$ & $9.50 \pm 0.04 \mathrm{c}$ & $0.85 \pm 0.03 \mathrm{~b}$ \\
& 110 & $0.31 \pm 0.01 \mathrm{~d}$ & $0.52 \pm 0.01 \mathrm{~d}$ & $1.10 \pm 0.04 \mathrm{~b}$ & $0.85 \pm 0.02 \mathrm{~b}$ \\
Coarse & 70 & $0.09 \pm 0.02 \mathrm{a}$ & $0.24 \pm 0.03 \mathrm{a}$ & $1.76 \pm 0.53 \mathrm{c}$ & $0.55 \pm 0.02 \mathrm{a}$ \\
& 90 & $0.16 \pm 0.02 \mathrm{~b}$ & $0.35 \pm 0.01 \mathrm{~b}$ & $0.60 \pm 0.06 \mathrm{a}$ & $0.55 \pm 0.02 \mathrm{a}$ \\
& 110 & $0.15 \pm 0.01 \mathrm{~b}$ & $0.44 \pm 0.09 \mathrm{bc}$ & $0.82 \pm 0.08 \mathrm{ab}$ & $0.81 \pm 0.01 \mathrm{~b}$ \\
\hline
\end{tabular}

Note. Values followed by different letters in each column indicate significant differences $(\mathrm{P} \leq$ $0.05)$.

\section{Cohesiveness}

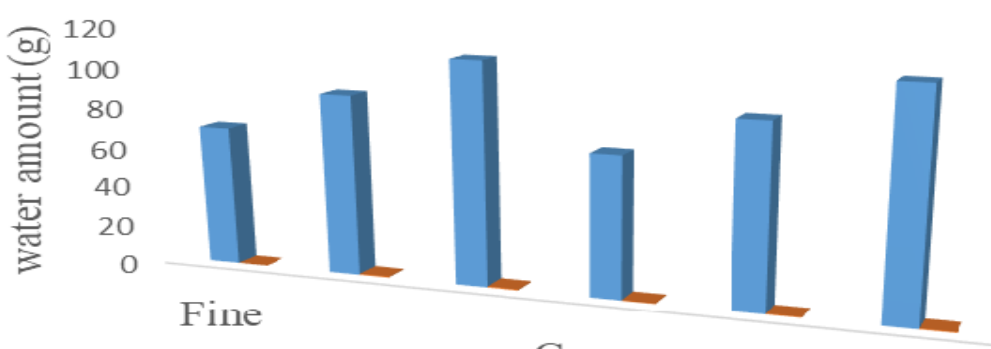

\section{Coarse}

Flours

- Water amount (g) $\quad$ cohesiveness

Figure 1. Bread crumb Cohesiveness of the flours on the different water amount addition

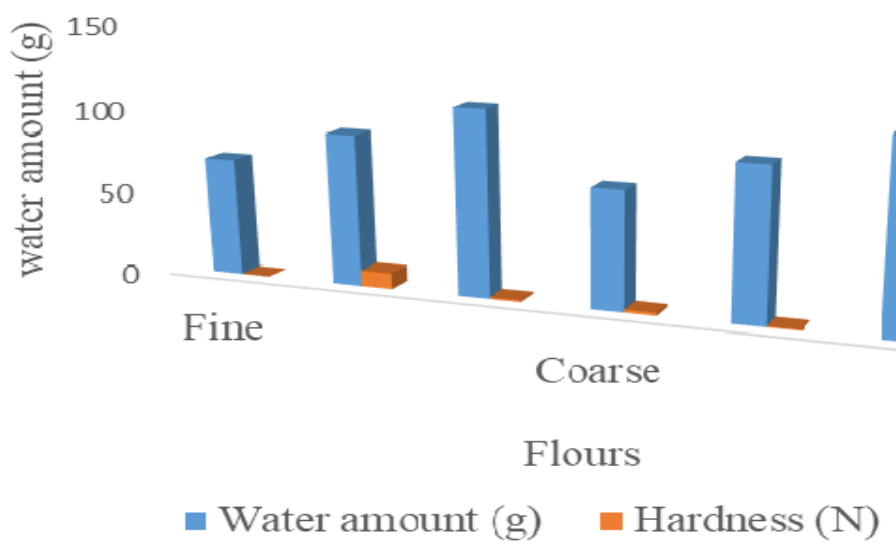

Figure 2. Fine and cores flours bread crumb hardness changes on the different amount of water addition 
In this study, traditional results have presented by the mixture of corn and rice flour, buffering effect was shown by corn flour, for manufacturing of gluten-free bread with a very thin preparation (no additives) this type of flour was very helpful. Regression equation (Table 1) showed the relation only to wheat bread, this was shown in formerly research. Shown in this work, Gluten-free bread has a lack of such description. in earlier studies, relations between the physical properties of bread and process parameters described by the regression equations, it is only relating to wheat bread (Ryzylo, 2014b). in this study, the canonical form was planned by the additional alteration of the second-degree polynomial equation (Table 2 ).

Table 2. Some characteristics of rice based gluten- free bread were affected by the recipe, according to flour particles size and used water amount

\begin{tabular}{lllll}
\hline & & Moisture $(\%)$ & specific volume $(\mathrm{ml} / \mathrm{g})$ & Weight loss $(\mathrm{g})$ \\
\hline \multirow{3}{*}{ Particle size } & Overall mean & 37.82 & 4.14 & 4.61 \\
& Fine & $38.43 \mathrm{~b}$ & $2.60 \mathrm{a}$ & $2.83 \mathrm{a}$ \\
& Coarse & $37.22 \mathrm{a}$ & $5.74 \mathrm{~b}$ & $6.44 \mathrm{~b}$ \\
Water amount (\%) & 70 & $32.39 \mathrm{a}$ & $3.04 \mathrm{a}$ & $1.65 \mathrm{a}$ \\
& 90 & $39.24 \mathrm{~b}$ & $4.25 \mathrm{~b}$ & $4.90 \mathrm{~b}$ \\
& 110 & $41.85 \mathrm{c}$ & $5.20 \mathrm{c}$ & $7.25 \mathrm{c}$ \\
\hline
\end{tabular}

Note. Values tailed by significant differences $(\mathrm{P} \leq 0.05)$ shown by the different letters in each column and each parameter.

One of the grittiest parameters for bread quality valuation is the bread volume (Kasprzak \& Rzedzicki, 2010). Negatively changes dough rheological properties and bread quality in the wheat flour are due to the addition of gluten-free ingredients, this application is in the case of wheat bread (Karaoglu, 2012). The regression equations describing the variations in the bread volume presented by (Table 1). And the hardness and the cohesiveness changes in fine and cores flour bread crumb with different amount of water (70-110 g) shown into Figure 1 and 2. In the recipe kind of raw material and the water amount addition were the significant factors on which the bread volume was significantly reliant, it is shown by the analysis of the results (Schoenlechner et al., 2010). Significant vagaries in bread volume caused the water amounts in the comparison with albumen and fat noticed by the who deliberate bread made with amaranth flour in the works, under the impact of rising levels of water addition, different types of natural gluten-free bread have not any studies and description of the qualitative changes (Lazaridou et al., 2007). In other studies, the effect of dissimilar levels of water addition has also been observed due to the due to the technological additives, significant changes in loaf volume gluten-free bread was developed (De la Hera et al., 2013). Type of additives was responsible for the changes (Lazaridon et al., 2007). According to this study, the major amount of water addition is required for the cornbread, with a $120 \%$ water addition the volume of the bread was great. confirming this study, with the addition of water of the dough, corn flour bread volume enlarged linearly (Schoenlechner et al., 2010). 


\section{MInstitute ${ }^{\text {Mink }}$}

The crumb was thick and the cornbread was not nicely swelled and stiff with the lesser amounts $80 \%$ and $100 \%$ of water addition. (Schober et al., 2005) clarified that in terms of viscosity, gluten absence in the dough is the main reason for the liquation of gluten-free dough. To be held in a way similar cake batter rather than tentative bread dough presented by this typical system (Hager \& Arendt, 2013). At the 90\% of water addition, the bread volume was the highest; though, bread was already collapsed with the additive. At $100 \%$ of water addition, bread made of rice and corn volume $\left(178.7 \mathrm{~cm}^{3}\right)$ was maximum. According to Hager et.al., 2012), cornbread was not much categorized by significantly high specific volumes as like rice bread. the crumb of bread from rice had the maximum brightness. gluten-free bread from the concentrate had less brightness and the bread crumb made by buckwheat flour had the slightest brightness. Similarly, different studies, a reduction in crumb whiteness was noticed when compared with the control sample (corn and potato starch) while the buckwheat flour amounts increased in the bread preparations (Wronkowska et al., 2013).

To assess the bread quality, the crumb texture parameters were used. Bread could not be measured which made with the fine flour and $70 \%$ of water content because to allow compression with full contact between the crumb and probe surface, its volume was not high. The hardness reduced significantly in the bread made with coarse flour compared to the ones obtained from the flour, the crumb texture parameters were measured (Macro \& Rosell, 2008). When increasing the water content in the recipe, a reduction of the hardness was observed. Although, bread made with coarse flour between the water content of $90 \%$ and $110 \%$ were not significant differences detected (Rosell, 2009). A lower bread specific volume results in greater hardness due to thicker crumb and more dense cells, it was due to hardness was contrariwise correlated with specific volume $(\mathrm{r}=0.8931 ; \mathrm{P} \leq 0.001)$. Hardness was contrariwise correlated with specific The crumb hardness of the rice bread obtained in this study was much lower than that reported for profitable gluten free bread (Matos \& Rosell, 2012), perhaps due to the use of starch in its place of flour.

The interior resistance or consistency of food structure quantifies by the cohesiveness. The breads made with the fine flour significantly increased. $70 \%$ and $90 \%$ hydration showed the significant effect of the water. The increases of the water content in the formulation due to the cohesiveness decreasing in parallel (Moore et al., 2004). In fact, a high significant correlation with the bread moisture content $(r=0.9008 ; \mathrm{P} \leq 0.001)$ showed by the cohesiveness. High susceptibility of the crumb to fracture and crumble indicated by the low cohesiveness. Besides hardness and cohesiveness, considering the volume results, the limited amount of water obstructed the intermolecular interface among ingredients and provoked water competition among ingredients in the breads obtained from $70 \%$ dough hydration (Parada \& Aguilera, 2011). Conversely, the water content in the breads made with coarse flour affected the springiness, indicative of the crumb elasticity besides its resilience. In those breads, the highest springiness led by the highest water content (Schober, 2005). The breads made of fine flour was observed high resilience value. The resilience values significantly increased by the water content improved. When $70 \%$ or $90 \%$ hydration was applied, only then observed the water content effect on resilience in the breads made of coarse flour. The loss of crumb elasticity is commonly related to Springiness and resilience and their reduction (Onyango, et al., 2011). 


\section{Macrothink}

However, on the relationships between dough and bread quality has no guide or fundamental knowledge to scientifically design gluten-free foodstuffs. Because of that, to predict the quality of the final bread, dealing with gluten-free both dough and bread level, will be really useful to decipher possible parameters. Recently, for identifying those potentially useful parameters some attempts have been. In fact, six rice flour-based gluten-free preparations designed and measured by Matos and Rosell (2013). In that study, mainly rice flour and rice flour combined with the potato and corn starches were used for the recipes, and others ingredients like protein sources (skim milk) Gluten-free bread making is also different than the gluten-containing foods, mainly owing to the restrictions associated to the amount of water, which is responsible of the dough consistency during mixing (Marco \& Rosell, 2008) but also affected dough fermentation (Gomez et al., 2013). In doing so, high specific volume was obtained with longer mixing time, when dough hydration was 80 , the mixing arm type did not have any significant effect due to the mixing arm also influences dough development and gluten-free bread quality.

Equally, bread volume and texture significantly affected when using $110 \%$ dough hydration the mixing arm and mixing speed. with the wire whip with low mixing speed and long mixing time ( $8 \mathrm{~min}$ ) achieve the higher specific volumes and softer breads. Moreover, during proofing, the low hydrated dough had low ability to retain the gas role. Whereas, the improved specific volume is due to the high hydrated doughs $(110 \%)$ endure longer fermentation time (Gomez et al., 2013).

Consequent improvement in the nutritional quality due to Fiber sources such as rice bran (Phimolsiripol et al., 2012) and inulin (Krupa-Kozak et al., 2012) have been added in gluten-free breads. Very recently, the fibers water-binding ability Psillium gum and sugar beet fibers have been added to gluten-free breads, $80 \%$ and water adsorption must be adapted. The water was added to the gluten-free bread recipe up to a sourdough- dough consistency of 230 $\pm 10 \mathrm{BU}$ and $180 \pm 10 \mathrm{BU}$ (Brabender Unit) it was according to the recent literature (Hager, A.S. et.al. 2012) and to the authors' premalinery studies (Mariotti, 2016) and on the basis of a subsequent research (Cappa et al., 2016). In order to make comparisons with some authors' findings (Mariotti et al., 2016), the sample containing sourdough, which is the most critical in terms of leavening properties and dough development, was here replicated at a $230 \mathrm{BU}$ level consistency. A Brabender, Farinograph (Brabender OHG, Duisburg, Germany; 300 g chamber, $250 \mathrm{C}$ ) was used for the water absorption levels (WA, \%) assessment (Matos, 2015). The remaining ingredients were added within the subsequent 2 min after pre-mixing for 5 minutes of powders. $15 \mathrm{~min}$ were taken for kneading. To be further Evaluation during proofing the resulting dough was divided into aliquots produced and analyzed to total four recipes.

SD230 (SD, having a farinographic consistency of $230 \pm 10 \mathrm{BU}$ );

SD180 (SD, having a farinographic consistency of $180 \pm 10 \mathrm{BU})$;

CY180 (CY, having a farinographic consistency of $180 \pm 10 \mathrm{BU})$;

SDCY180 (SDCY, having a farinographic consistency of $180 \pm 10 \mathrm{BU}$ ). 
Table 3. Water extraction, different gluten-free doughs recipe

\begin{tabular}{lllll}
\hline Ingredients & SD230 & SD180 & CY180 & SDCY180 \\
\hline Corn starch & $31 \pm 0.4$ & $32 \pm 0.3$ & $37 \pm 0.3$ & $30 \pm 0.3$ \\
Rice flour & $31 \pm 0.4$ & $30 \pm 0.2$ & $37 \pm 0.4$ & $31 \pm 0.3$ \\
Isolatedpea protein & $5 \pm 0.3$ & $6 \pm 0.2$ & $6 \pm 0.3$ & $6 \pm 0.4$ \\
Psyllium fiber & $1.1 \pm 0.1$ & $1.3 \pm 0.2$ & $1.5 \pm 0.2$ & $1.2 \pm 0.2$ \\
Hydroxylpropyl methylcellulose & $1.3 \pm 0.1$ & $1.3 \pm 0.2$ & $1.6 \pm 0.1$ & $1.2 \pm 0.2$ \\
Emulsifiers & $0.5 \pm 0.02$ & $0.4 \pm 0.02$ & $0.5 \pm 0.02$ & $0.4 \pm 0.01$ \\
Oil & $5.0 \pm 0.2$ & $5.0 \pm 0.3$ & $6.1 \pm 0.4$ & $4.9 \pm 0.4$ \\
Maltose & $3.3 \pm 0.2$ & $3.4 \pm 0.2$ & $4.0 \pm 0.3$ & $3.1 \pm 0.2$ \\
NaCl & $1.8 \pm 0.2$ & $1.8 \pm 0.2$ & $2.0 \pm 0.3$ & $1.7 \pm 0.3$ \\
SD & $20 \pm 0.5$ & $20 \pm 0.3$ & $0 \pm 0$ & $20 \pm 0.4$ \\
CY & $0 \pm 0$ & $0 \pm 0$ & $2 \pm 0.01$ & $2 \pm 0.02$ \\
\hline
\end{tabular}

\section{Conclusions}

A gluten-free diet is one only treatment the constant devotion for the Celiac disease. Celiac disease is a common colonic disorder. However, major content of wheat flour is gluten. For manufacturing of gluten-free products are Consuming starches, gums and hydrocolloids are the most prevalent method to imitate gluten structure. Many kinds of research confirmed the positive effect of sourdough on bread making. To improve the quality of GF bread, a gluten-free sourdough is a possible approach. A softer crumb and more reduced staling kinetics were used for the modern presence of the two leavening agents (SD and CY) resulted in well-developed end products characterized. In term of dough workability and end product quality, a lower consistency (180 BU instead $230 \mathrm{BU}$ ) demonstrated superior performance. More comprehensive researches in the field of gluten-free cereal-based products are necessary regarding the current increasing awareness of celiac disease due to superior diagnostic methods, more comprehensive researches.

\section{Acknowledgement}

The research receives specific grant from project no. IGA/2018/003 internal grant agency Tomas Bata University in Zlin, Czech Republic.

\section{References}

Arendt, E. K. O. B., Schober, T. J., Gallagher, E., \& Gormley, T. R. (2002). Development of gluten free cereal products. Farm Food, 12, 21-27.

Brites, C., Trigo, M. J., Santos, C., Collar, C., \& Rosell, C. M. (2010). Maize-based gluten free: influence of processing parameters on sensory and instrumental quality. Food Bioprocess Technology, 3, 707-715. https://doi.org/10.1007/s11947-008-0108-4 


\section{Macrothink}

Journal of Food Studies ISSN 2166-1073 2019, Vol. 8, No. 1

Cauvain, S. P. (1998). Other cereals in breadmaking. In S. P. Cauvain, \& L. S. Young (Eds.), Technology of breadmaking (pp. 330-346). Blackie Academic \& Professional, London. https://doi.org/10.1007/978-1-4615-2199-0_13

Corsetti, A. (2013). Technology of sourdough fermentation and sourdough applications. In M. Gobbetti, \& M. Ganzle (Eds.). Handbook on Sourdough Biotechnology (pp. 85-103). Springer: New York, NY, USA. https://doi.org/10.1007/978-1-4614-5425-0_4

Cappa, C., Barbosa-Cánovas, G. V., Lucisano, M., \& Mariotti, M. (2016). Effect of high pressure processing on the baking aptitude of corn starch and rice flour. LWT Food Sci. Technol., 73, 20-27. https://doi.org/10.1016/j.lwt.2016.05.028

Cappa, C., Lucisano, M., \& Mariotti, M. (2013). Influence of Psyllium, sugar beet fibre and water on gluten-free dough properties and bread quality. Carbohydr. Polym., 98, 1657-1666. https://doi.org/10.1016/j.carbpol.2013.08.007

De la Hera, E., Gomez, M., \& Rosell, C. M. (2013a). Particle size distribution of rice flour affecting the starch enzymatic hydrolysis and hydration properties. Carbohydrate Polymers, 98, 421-427. https://doi.org/10.1016/j.carbpol.2013.06.002

De la Hera E., Talegón M., Caballero P., \& Gómez M., (2013). Influence of maize flour particle size on gluten-free breadmaking. J. Sci. Food Agric., 93, 924-932. https://doi.org/10. 1002/jsfa.5826

Gallagher, E., Gormley, T. R., \& Arendt, E. K. (2004). Recent advances in the formulation of gluten-free cereal-based products. Trends Food Sci Technol, 15(3-4), 143-152. https://doi.org/10.1016/j.tifs.2003.09.012

Gallagher, E., \& Gormley, T. R. (2002). The quality of gluten free breads produced at retail outlets. Research report. The National Food Centre, Dublin

Gallagher, E., Gormley, T. R., \& Arendt, E. K. (2003). Crust and crumb characteristics of gluten free breads. J Food Eng, 56(2-3), 153-161. https://doi.org/10.1016/S0260-8774 (02)00244-3

Gomez, M. (2013). Talegón and de la Hera E, Influence of mixing on quality of gluten-free bread. J Food Quality, 36, 139-145. https://doi.org/10.1111/jfq.12014

Han, H. M., Cho, J. H., Kang, H. W., \& Koh, B. K. (2012). Rice varieties in relation to rice bread quality. Journal of the Science of Food and Agriculture, 92, 1462-1467. https://doi.org/10.1002/jsfa.4727

Hager, A. S., Wolter, A., Czerny, M., Bez, J., Zannini, E., Arendt, E. K., \& Czerny, M. (2012). Investigation of product quality, sensory profile and ultrastructure of breads made from a range of commercial gluten-free flours compared to their wheat counterparts. Eur. Food Res. Technol, 235, 333-344. https://doi.org/10.1007/s00217-012-1763-2

Hager A. S., \& Arendt, E. (2013). Influence of hydroxyl propyl methyl cellulose (HPMC), xanthan gum and their combina- tion on loaf specific volume, crumb hardness and crumb grain characteristics of gluten-free breads based on rice, maize, teff and buckwheat. Food Hydrocolloids, 32, 195-203. https://doi.org/10.1016/j.foodhyd.2012.12.021

Krupa-Kozak, U., Altamirano-Fortoul, R., Wronkowska, M., \& Rosell, C. M. (2012). Breadmaking performance and technological characteristic of gluten-free bread with inulin 
supplemented with calcium salts. Eur Food Res Technol, 235, 545-554. https://doi.org/10.1007/s00217-012-1782-z

Kasprzak, M., \& Rzedzicki, Z. (2010). Effect of pea seed coat admixture on physical properties and chemical composition of bread. Int. Agrophys., 24, 149-156.

Karaoğlu, M. M. (2012). Effect of Cephalaria syriaca addition on rheological properties of composite flour. Int. Agrophys., 26, 387-393. https://doi.org/10.2478/v10247-012-0054-2

Lazaridou, A., Duta, D., Papageorgiou, M., Belc, N., \& Biliaderis, C. G. (2007). Effects of hydrocolloids on dough rheology and bread quality parameters in gluten-free formulations. $J$. Food Eng., 79, 1033-1047. https://doi.org/10.1016/j.jfoodeng.2006.03.032

Mendoza, N. (2005). Coeliac disease: An overview of the diagnosis, treatment and management. Nutr Bull, 30(3), 231-236. https://doi.org/10.1111/j.1467-3010.2005.00513.x

Moore, M. M., Schober, T. J., Dockery, P., \& Arendt, E. K. (2004). Textural comparisons of gluten-free and wheat-based doughs, batters, and breads. Cereal Chem, 81(5), 567-575. https://doi.org/10.1094/CCHEM.2004.81.5.567

Marco, C., \& Rosell, C. M. (2008). Breadmaking performance of protein enriched gluten-free breads. European Food Research and Technology, 227, 1205-1213. https://doi.org/10.1007/s0 0217-008-0838-6

Matos, M. E., \& Rosell, C. M. (2012). Relationship between instrumental parameters and sensory characteristics in gluten-free breads. European Food Research and Technology, 235, 107-117. https://doi.org/10.1007/s00217-012-1736-5

Matos, M. E., \& Rosell, C. M. (2013). Quality indicators of rice based gluten free bread-like products: relationships between dough rheology and quality characteristics. Food Bioprocess Technol, 6, 2331-2341. https://doi.org/10.1007/s11947-012-0903-9

Marco, C., \& Rosell, C. M. (2008). Breadmaking performance of protein enriched, gluten-free breads. Eur Food Res Technol, 227, 1205-1213. https://doi.org/10.1007/s00 217-008-0838-6

Mariotti, M., Cappa, C., Picozzi, C., Tedesco, B., Fongaro, L., \& Lucisano, M. (2016). Compressed yeast and Type I gluten-free sourdough in gluten-free breadmaking. J. Food Bioprocess Technol..

Matos, M. E., \& Rosell, C. M. (2015). Understanding gluten-free dough for reaching breads with physical quality and nutritional balance. J. Sci. Food Agric., 95, 653-661. https://doi.org/10.1002/jsfa.6732

Onyango, C., Mutungi, C., Unbehend, G., \& Lindhauer, M. (2009a). Creep-recovery parameters of gluten-free batter and crumb properties of bread prepared from pregelatinised cassava starch, sorghum and selected proteins. Intl J Food Sci Technol, 44(12), 2493-9, 1365-2621.

Parada, J., \& Aguilera, J. M. (2011). Review: Starch matrices and the glycaemic response. Food Science and Technology International, 17, 187-204. https://doi.org/10.1177/1082013 210387712

Phimolsiripol, Y., Mukprasirt, A., \& Shoenlechner, R. (2012). Quality improvement of rice-based gluten-free bread using different dietary fibre fractions of rice bran. J Cereal Sci, 
56, 389-395. https://doi.org/10.1016/j.jcs.2012.06.001

Rosell, C. M. (2009). Enzymatic manipulation of gluten-free breads. In E. Gallagher (Ed.) Gluten-free food science and technology (pp. 83-89). Wiley-Blackwell, London. https://doi.org/10.1002/9781444316209.ch6

Raineri, A. (2011). Messa a Punto di Una Formulazione per Pane Gluten-Free a Lievitazione Naturale. Bachelor's Thesis, Facoltà di Scienze Agrarie e Alimentari, Università degli Studi di Milano, Milan, Italy

Różyło R. (2014b). Effect of process modifications in two cycles of dough mixing on physical properties of wheat bread baked from weak flour. Food Bioprocess Technol., 7, 774-783. https://doi.org/10.1007/s11947-013-1100-1

Różyło, R., Rudy, S., Krzykowski, A., \& Dziki, D. (2015b). Novel application of freeze-dried amaranth sourdough in gluten-free bread production. J. Food Process Eng., 38, 135-143. https://doi.org/10.1111/jfpe.12152

Różyło R. (2014a). New potential in using millet-based yeast fermented leaven for composite wheat bread preparation. J. Food Nutr. Res., 53(3), 240-250.

Schober, T. J., Messerschmidt, M., Bean, S. R., Park, S. H., \& Arendt, E. K. (2005). Gluten-free bread from sorghum: quality differences among hybrids. Cereal Chem, 82(4), 394-404. https://doi.org/10.1094/CC-82-0394

Schober, T. J. (2009). Manufacture of gluten-free speciality breads and confectionery products. In E. Gallagher (Ed.), Gluten-free food science and technology (pp. 130-180). Wiley-Blackwell, Oxford.

Schoenlechner, R., Mandala, I., Kiskini, A., Kostaropoulos, A., \& Berghofer, E. (2010). Effect of water, albumen and fat on the quality of gluten-free bread containing amaranth. Int. J. Food Sci. Technol., 454, 661-669. https://doi.org/10.1111/j.1365-2621.2009.02154.x

Schober, T. J., Messerschmidt, M., Bean, S. R., Park, S-H., \& Arendt, E. K. (2005). Gluten-free bread from sorghum: Quality differences among hybrids. Cereal Chem., 824, 394-404. https://doi.org/10.1094/CC-82-0394

Sakac, M., Torbica, A., Sedej, I., \& Hadnadev, M. (2011). Influence of breadmaking on antioxidant capacity of gluten free breads based on rice and buckwheat flours. Food Res. Int. J., 449, 2806-2813. https://doi.org/10.1016/j.foodres.2011.06.026

Wronkowska, M., Haros, M., \& Soral-Śmietana, M., (2013). Effect of starch Substitution by buckwheat flour on glutenfree bread quality. Food Bioprocess Technol., 6, 1820-1827. https://doi.org/10.1007/s11947-012-0839-0

Wronkowska, M., \& Soral-Śmietana, M. (2008). Buckwheat flour - a valuable component of gluten-free formulations. Polish J. Food Nutrition Sci., 581, 59-63.

\section{Copyright Disclaimer}

Copyright for this article is retained by the author(s), with first publication rights granted to the journal.

This is an open-access article distributed under the terms and conditions of the Creative Commons Attribution license (http://creativecommons.org/licenses/by/3.0/). 